\title{
SOCIO-DEMOGRAPHIC AND PSYCHOLOGICAL DETERMINANTS OF LEISURE TIME PHYSICAL ACTIVITY AMONG ADOLESCENTS IN NIGERIA
}

\author{
Solomon B. Oguntuase ${ }^{1 i}$, \\ Yanlin Sun', \\ Tolulope C. Apata ${ }^{3}$, \\ Jephtah O. Ogunsanya ${ }^{4}$ \\ ${ }^{1}$ School of Sports Science, \\ Tianjin University of Sport, \\ Tianjin, China \\ 2School of PE and Educational Science, \\ Tianjin University of Sport, \\ Tianjin, China \\ ${ }^{3}$ Department of Human Kinetics, \\ University of Ibadan, \\ Ibadan, Nigeria \\ ${ }^{4}$ Department of Physical and Health Education, \\ Emmanuel Alayande College of Education, \\ Oyo State, Nigeria
}

\begin{abstract}
:
Despite the numerous benefits associated with leisure time physical activity (LTPA), it is quite worrisome that the habit of regularly engaging in LTPA is rare among Nigerians, especially among adolescents who are found in myriads of sedentary lifestyle behaviour as a result of technological and economical advancement. The present study examined socio-demographic and psychological determinants of LTPA among adolescents in Nigeria. A cross-sectional study was conducted and multistage sampling technique was employed to recruit 1200 adolescents (Male $=59.7 \%$; Female $=40.3 \%$; Age: $10-19$ years) from twelve secondary schools in Southwest States, Nigeria. Physical Activity SelfEfficacy for Adolescent (PASE), The Physical Activity and Leisure Motivation Scale (PALMS), Activity Questionnaire for Adults and Adolescents (AQuAA) and Selfdeveloped Socio-demographic Questionnaire were used to collect the data. Data were analyzed using statistics of frequency count, percentages \& Multiple Regression. The result of the study showed that socio-demographic $\left(\mathrm{F}(8,1191)=4.980 ; \mathrm{p}<.05 ; \mathrm{R}^{2}=.28\right)$ accounting for $28 \%$ of its variance and psychological factors $(\mathrm{F}(2,1197)=31014.342$, $\mathrm{p}<$ $.05 ; \mathrm{R}^{2}=.99$ ) accounting for $99 \%$ of its variance) were significant. Based on the findings,
\end{abstract}

${ }^{i}$ Correspondence: email oguntuasesolomon@yahoo.com 
adolescents in Southwest states in Nigeria do not meet the World Health Organization recommendations on physical activity. Both socio-demographic and psychological factors significantly determined LTPA and these factors could be taken into account in the development of interventions to increase LTPA levels throughout the life course among adolescents in Nigeria.

Keywords: leisure-time physical activity, socio-demographic, motivation, self-efficacy, adolescents

\section{Introduction}

The recognising benefits of engaging in leisure time physical activity (LTPA) have become a strategic health importance which contribute to the growth and development of adolescents and thus attracted the attention of individuals, groups and world organizations. International agencies such as World Leisure Organization (WLO), World Tourism Organization (WTO), World Travel and Tourism Organization (WTTO), International Council for Physical Health Education, Recreation Sport and Dance (ICHPER.SD), World Health Organization (WHO), the European Union (EU), the United States Department of Health and Human Services (USDHHS) etc are actively involved in propagating physical leisure time activity programmes around the world because of its tremendous contributions to individuals and community development.

Physical inactivity is one of the most significant contributors to the global burden of disease (Lee et al. 2012). According to World Health Organisation (WHO) (2015), physical inactivity is the fourth leading global risk factor for mortality, causing about 3.2 million deceases. The lack of PA among adolescents is worrisome, as PA of adolescents has shown to track into adulthood, meaning that low PA levels persist to a certain extent from adolescence to adulthood (Telama 2009; Kjonniksen, Torsheim \& Wold, 2008). Promotion of PA is thus important for all age groups, and most importantly for adolescents. Studies have shown that there are many children and adolescents who are relatively inactive and do not meet the required level of engaging in physical activity (de Moraes et al., 2013; Guthold et al., 2010). WHO (2018) reported that globally, more than $80 \%$ of the world's adolescent population is insufficiently physically active and 1 in 4 adults is not active enough. It is alarming and overwhelming with the menace upsurge of physical inactivity in most societies around the globe. The menace occurs not only in developed societies, but also in developing and under-developed societies (Muller, Khoo \& Lambert, 2013; Hallal et al., 2012).

WHO (2014) reported that physical inactivity levels in Africa are generally consistent between different genders, ethnicities and income levels, while half of all the adults are inactive. In addition, Guthold et al. (2010) indicated that only $8 \%$ to $35 \%$ of African youth meet the recommendation level of engaging in physical activity for 60 minutes a day in at least 5 days in a week. A Plethora of studies have reported lower level 
of participation in PA in Africa than Europe and other developed communities (Oyeyemi et al., 2016; Mukona et al., 2016; Micklesfield et al., 2014).

Forming positive habits of participating in LTPA is an important way of recharging vitality and this requires not just the knowledge of the consequences of involvement or not, but also associate with the current status of physical activity of the present younger generation and the factors that determine it (Lo et al., 2015). There are numerous factors that determine level of participation in LTPA. These include demographic, economic, psychological, social, environmental, administrative, ecological, organisational and cultural. This research focused on socio-demographic and psychological factors.

Socio-demographic factors play a crucial and immense role in engaging in LTPA. Studies have found that socio-demographic factors that influence participation in LTPA includes age, gender, education level, socioeconomic status, parental support, peers and friends (Payne, Townsend \& Foster, 2013; Oyeyemi et al., 2016; Fitzgerald, Fitzgerald \& Aherne, 2012; McMinn et al., 2008; Loucaides, 2009; Shokrvash et al., 2013). Payne et al. (2013) proved that along with the increasing pupils' age, their participation in active forms of recreation declines, and this occurs majorly among girls. A study by Marques et al. (2015) examined the link between socio-demographic factors and engagement in the recommended PA level for Portuguese adults revealed that age was not significantly related with PA.

Gender is another important factor that determines participation in LTPA. A study carried out by Lubowiecki-Vikuk and Biernat (2017) showed that as for girls, the risk of lack of movement was more than 1.4 times higher than among boys. As revealed by Jandric (2010) that the difference in social role of boys and girls lead to a different participation and understanding towards PA participation, the author further showed that boys were more likely to be physically active than girls, because girls recorded significantly fewer activities involving games than the boys did. Considering lifestyle as a whole includes religious aspects which could determine participation in LTPA. It has been shown that religiosity/spirituality is associated longevity of life suggesting a protective influence on healthy population with $18 \%$ reduced risk of mortality (Chida et al. 2009). Nagel and Sgoutas-Emch (2007) identified a significant positive association between religious involvement (spiritual experience, praying and church attendance) and physical activity in adolescents as well as a negative correlation with alcohol consumption. Benjamins (2012) found that there is a stronger influence of one's religious belief on health promotion behaviour, which is associated with physical activity involvement, but not diet.

Ethnicity/race has been studied to contribute to the determinant and demonstration of LTPA behaviour. Evaluation of National Health Interview Survey (NHIS) in 2007 found significant differences in PA across different racial groups (Saffer, Dave \& Grossman 2011). Adegoke and Oyeyemi (2011) showed that ethnicity was partly associated with high prevalence of physical inactivity. The study further showed that participants who belong to the Hausa ethnic group reported the highest prevalence of 
physical inactivity and they were more likely to be physically inactive and less likely to be moderately active than their counterparts from other ethnic groups.

Level of education and socioeconomic status of parents are two factors that go together to determine LTPA lifestyle and participation of adolescents among different individuals and communities. A study by Marques et al., (2015) among Portuguese found that educational levels were not associated with meeting PA recommendations for men, but were for women. Similarly, Shibata, Oka, Nakamura, Muraoka (2009) results found that for men and women despite the variance in cultural practices, the most educated among women were more likely to engage and attain the recommended PA level. However, this was not seen among men counterparts. On the other part, socio-economic status (SES) of parents is crucial to participation of children and adolescents in LTPA. Rimmer et al. (2002) highlighted likely reasons for low participation in PA among low SES individuals. First, these individuals live in communities with fewer recreational facilities or park, lack enough funds to purchase home exercise equipment, lack social support or to lead a physically active lifestyle, and also lack understanding about the health benefits of activity. Marques et al., (2015) showed that higher SES adults are more likely to follow preventive programs and health-promoting behaviour, whether due to greater motivation or access to resources. Dias-da-Costa, et al., (2005) revealed that SES is a significant correlate of PA. The authors added that men who belong to high SES and women that belong to middle SES were linked to meeting the recommendation of participating in PA.

The rate and frequency at which an individual participates in LTPA is essential to personal well-being. World Health Organization (WHO) recommends that children and youth aged 5-17years should accumulate at least 60min of moderate-to-vigorousintensity PA daily (WHO, 2017b). Ndagire, Muyonga and Nakimbugwe (2019) study found inadequate levels of PA being reported among children and adolescent students in Uganda. A study conducted by Liu and Dai (2017) revealed that on average, the amount of physical activity in Chinese university students is very low, and male students involved in more PA than their female counterparts. Oyeyemi et al., (2016) showed that school is being the most common context for Nigerian adolescents' physical activity. Sedibe et al. (2014) in a qualitative study revealed that school is a common and an important outlet for South African adolescents to engage in physical activity. Wojtyła et al. (2011) demonstrated that participation in PA among Polish youths is only limited to physical education classes.

Number of children in the family and parental influence has been found to determine LTPA participation as this play a great role in actualizing and meeting the recommendation of WHO about PA. Duncan et al. (2004) found that children who had older siblings were more likely to spend time in moderate-intensity PA, while this is in contrast to the study conducted by Wang and Qi (2016) who found that there was no significant difference in MVPA time between adolescents living with one sibling and those without any siblings. Bagley, Salmon and Crawford (2006) indicated that girls with more siblings spent more minutes per day in PA compared with girls without siblings. 
Davison (2004) reported that siblings influenced PA behaviour of children and adolescents. Moreover, parental influences such as support and modelling have been identified as significant factor for PA participation in children and adolescents (Sallis, Prochaska \& Taylor, 2000). Longitudinal study by Kahn et al. (2008) found that mother's PA was associated with both male and female adolescents' participation in PA. In their meta-analysis, Yao and Rhodes (2015) concluded that the relationship between father-son was higher than that of mother-son modelling, while the same occurred between motherdaughter and father-daughter. Aljayyousi et al (2019) indicated that some students highlighted that their families give priority to work, personal commitments and academic achievement over involvement in PA. They added that father spend long hours at work and the mother would take care of family members and doing housework, which negatively impacted physical activity time and choices.

Psychological factors have been found to influence and determine involvement and participation of adolescents in LTPA. Different psychological factors help an individual to belief in oneself, values to participate in LTPA as a result of personal gains and development. Psychological factors that encourage the younger generation to develop interest and habit of being physically active is crucial to their personal wellbeing. According to the theory of motivation by Deci and Ryan (1985), an individual's attitude is a result of an internal or external motivation or lack of it. An individual becomes motivated either internally or externally in high or low levels or do not really become motivated and they resulted quitting the activity. Cagla et al. (2009) explained that understanding the factors that motivate people to participate in LTPA is important to encourage persistence in physical activity participation which is advantageous to the development of physical and psychological well-being. According to Chiu and Kayat (2010), the motivation for physical activity was found to be the largest contributor or effect on the frequency and magnitude of participation in LTPA among undergraduates at local public universities. Besides, Andrea (2012) in Jonathan (2016) findings on frequency of physical activity and the time spent in physical activity was found to be positively related to intrinsic motivation, integrated regulation, and identified regulation. In their study, Ajibua, Olorunsola and Bewaji (2013) found that most respondents maintained that they participated in LTPA because of personal motivation/interest. Biddle and Mutrie (2008) found that the common motives for participating in PA among children and youths were fun, skill development affiliation, fitness, success and challenge, while the motives for adults change across stages of their lifecycles.

Self-efficacy as a psychological construct is a central component of the social cognitive theory (Bandura, 1997), which refers to a person's belief in his/her ability to execute behaviours necessary to achieve desired outcomes. Studies have indicated that self-efficacy to overcome barriers to physical activity is a significant predictor of adolescents' physical activity participation (Allison, Dwyer \& Makin, 1999; Petosa et al., 2005). The findings by Chiu and Kayat (2010) indicated that high self-efficacy and motivation for physical activity would likely increase the rate of participation in leisure time physical activities among undergraduate students. In other words, the higher 
students' beliefs in self-efficacy for physical activity, the more frequent their participation in LTPA. Hagger, Chatzisarantis and Biddle (2002) showed moderate correlations between self-efficacy and physical activity participation among both young and older people. Liu, and Dai (2017) found that vigorous PA significantly correlated with selfefficacy to overcome social environment barriers and responsibility barriers in female students.

Nigeria is the most populous country in sub-Sahara Africa with highest number of youths aged between 10-24years (Population Reference Bureau, 2021). Physical inactivity related Non-Communicable Diseases (NCDs) morbidity and mortalities among adolescents escalate on daily basis in the country. The adolescents in Nigeria especially those in secondary schools who are supposed to be active and participate freely in LTPA are only focused and concentrated on sedentary leisure lifestyle activities and shy away from LTPAs such as walking, running, cycling, swimming, playing table tennis, volleyball, football, etc. They embraced such activities as playing video games, watching television, surfing and playing internet games, playing computer games among others. These occur due to the influx of advanced technological devices, availability and easy accessibility to these devices with little or no control and supervisions on the usage. The total immersion in these sedentary-related leisure time activities has caused drastic decline in LTPA of adolescents which in turn could lead to increase in overweight, obesity, risk of cardiovascular diseases, high blood pressure, osteoporosis, anxiety, depression, low self-esteem, etc. Moreover, most adolescents in secondary schools in Nigeria are only limited to participate in physical activity exercises conducted in schools and during physical education classes due to the organised environment in schools which cannot satisfy meeting the recommendation guidelines of PA for adolescents. There is the need for these adolescents to involve in regular, moderate to vigorous LTPA after school in order to meet the recommended physical activity level, avoid sedentary lifestyle and promote healthy living.

A plethora of studies have been conducted on physical activities and LTPA with different population groups and professions in Nigeria. Examples include quantification of LTPA among university students; and perceived motives for participation in LTPA among tertiary institution employees (Ajibua \& Dominic, 2018; Ajibua, et al., 2014); psychosocial correlate of PA participation among university students (Awotidebe et al, 2014); pattern and associated factors of PA among adolescents (Oyeyemi et al., 2016); prevalence and correlates of LTPA among adults in urban settings (Akarolo-Anthony \& Adebamowo, 2014); PA and outdoor leisure time physical exercise among adults (Chigbu et al, 2020). From these studies, there are varying results on the levels of participation in LTPA. Also, most of these studies focused on the adolescents in university and adults in various professions in the community. Yet no studies have reported meeting the recommendation guidelines for PA in different population groups. From the foregoing, it can be deduced that the level of LTPA was not given maximum consideration especially among adolescents in secondary schools in Nigeria. Despite the lack of evidence and varying data on physical activity level and LTPA of general population in Nigeria, there 
is dearth of studies on LTPA of adolescents in secondary schools in Nigeria and factors that could determine their participation. Therefore, understanding the sociodemographic and psychological determinants of LTPA at the earliest stages of life is crucial for targeted interventions tailored to increase participation levels throughout the life course among adolescents in Nigeria. Hence, this study was aimed at investigating socio-demographic and psychological determinants of LTPA among adolescents in Southwest States, Nigeria.

\section{Methods}

\subsection{Participants}

One thousand two hundred (1200) secondary school students of Southwest States, Nigeria participated in this cross-sectional survey (59.7\% boys and $40.3 \%$ girls). The age range was between 9 and 19years. Multi-stage sampling technique was employed to select the participants. The participants were from Junior secondary school 1-3 and Senior secondary school 1-3 (JSS1 $=11 \%$, JSS2 $=24.1 \%$, JSS3 $=16.5 \%$, SSS1 $=12.3 \%$, SSS2 $=26 \%$ and SSS3 $=10.1 \%$ ) from three different Southwest (Oyo, Ondo and Osun) States in Nigeria. The participants' ethnicity was (Yoruba 65\%, Igbo 28\% and Hausa 6.2\%), the residence (urban $45.4 \%$, sub-urban $39.9 \%$ and rural $14.7 \%$ ) areas.

Southwest region is one of the six geo-political zones in Nigeria. The six geopolitical zones are North-Central (Middle Belt), North-East, North-West, South-East, South-South and South-West. Each zone comprises 6 states. The six (6) Southwest states are Oyo, Ogun, Lagos, Ondo, Osun and Ekiti. The ethnic group in this Southwest region is majorly Yoruba tribe with many dialects in each state. Three (3) states out of six (6) Southwest States were selected for this study. The selected states were Oyo, Osun and Ondo. Participants were selected from Four (4) secondary schools in each state totaling twelve (12) different secondary schools represented in this study. Both government and private secondary school students were represented in the study.

\subsection{Measures}

Socio-demographic information of age (between 9 and 19years), gender (male and female), religion (Christianity, Islam, Traditional and Others), ethnicity (Yoruba, Igbo and Hausa), parent's level of education (No formal education, primary, secondary, OND/NCE, B.Sc/HND, postgraduate and others), parent's socioeconomic status (higher, middle and lower), frequency of participation in LTPA (regular, periodic and sporadic), number of children in the family and family supports (father, mother, both parents, siblings and friends) were measured.

To measure psychological variables, Motivation of physical leisure time of the participants was assessed using original adapted 'The Physical Activity and Leisure Motivation Scale' (PALMS) developed by Zach, Bar-Eli, Morris and Moore (2012), which was found to yield sound psychometric properties. The PALMS questionnaire consists of forty (40) items rated on a 5-point Likert scale from 1 (strongly disagree) to 5 (strongly 
agree). It has six subscales of mastery, physical condition, affiliation, psychological condition, appearance, family and friends' expectations, health professionals' and employers' expectations, enjoyment, and competition/ego. The reported internal consistencies of the subscales were between .63 and .96 on Cronbach's alpha scale. Selfefficacy of the participants was assessed using eight (8) items Physical Activity SelfEfficacy for Adolescent developed by Dishman, Hales, Sallis, Saunders, Dunn, BedimoRung \& Ring (2010). The 5-point Likert scale ranged from 1 (strongly disagree) to 5 (strongly agree). The reported internal consistency of the scale was 0.82 on Cronbach's alpha scale. Activity Questionnaire for Adults and Adolescents (AQuAA) developed by Chinapaw et al. (2009) was used to measure LTPA of the participants. This questionnaire, that includes questions about frequency and duration of a range of physical activities, has shown to be fairly to moderately reliable.

\subsection{Procedure}

Permission to conduct the study was obtained from the Local Authority on Secondary School Education and the school principals of various schools. Students participated in the study voluntarily after directions and instructions from the school authorities. Prior to answering the questionnaire, participants were instructed to respond to the questions individually and as honestly as possible and were told that there were no right or wrong answers. The survey was carried out during free periods on class timetable in order not to interfere with the normal school and classroom activities. Participants completed the questionnaire in about 20 minutes with the help of the researchers and assistants who guided the participants.

\subsection{Data Analyses}

Descriptive statistics of frequency and percentages were conducted to summarise participants' characteristics. Also, an inferential statistic of regression at $5 \%$ alpha level was carried out to determine socio-demographic (age, gender, religion, ethnicity, parent's level of education, socioeconomic status, frequency of participation in LTPA, number of children and family supports) and psychological variables (self-efficacy and motivation). All statistical analyses were performed using IBM SPSS Statistics 22.0 (IBM Corp., Armonk, USA).

\section{Results}

Table 1 shows the demographic characteristics of the respondents (males 716 (59.7\%); females $484(40.3 \%)$. Age ranged between 10 and 11years constituted $50(4.2 \%), 12$ and 13 years 477(39.8\%), 14 and 15 years 459(38.3\%), 16-17years $178(14.8 \%)$ and between 18 and19years constituted 36(3.0\%). The classes of respondents represented were [JSS1 132 (11\%); JSS2 289 (24.1\%); JSS3 198 (16.5\%); SSS1 148 (12.3\%); SSS2 312 (26\%); SSS3 121 $(10.1 \%)$ ]. Religion practiced by the respondents [Christianity 836 (69.7\%); Islam 331 (27.6\%); Traditional 27 (2.3\%); Others $6(.5 \%)$ ]. The ethnicity of the respondents were 
[Yoruba 785 (65.4\%); Igbo 341 (28.4\%); Hausa 74 (6.2\%)]. The parents' education levels of the respondents [No formal education 173 (14.4\%); Primary school 214 (17.8\%); Secondary school 268 (22.2\%); Ordinary National Diploma/Nigeria College of Education (OND/NCE) 182 (15.2\%); Bachelor Degree/Higher Diploma Degree (BSc/HND 318 (26.5\%); Postgraduate $45(3.8 \%)$ ]. The parental socio-economic status [Lower 629(52.4\%); Middle 443(36.9\%); Higher 128(10.7\%)].

Table 1: Demographic characteristics of the respondents

\begin{tabular}{|c|c|c|}
\hline Items & Characteristics & n (\%) \\
\hline \multicolumn{3}{|c|}{ Gender } \\
\hline & Male & $716(59.7)$ \\
\hline & Female & $484(40.3)$ \\
\hline \multicolumn{3}{|l|}{ Age } \\
\hline & $10-11$ years & $50(4.2)$ \\
\hline & 12-13years & $477(39.8)$ \\
\hline & $14-15$ years & 459 (38.3) \\
\hline & $16-17$ years & $178(14.8)$ \\
\hline & 18-19years & $36(3.0)$ \\
\hline \multicolumn{3}{|l|}{ Class } \\
\hline & JSS1 & $132(11.0)$ \\
\hline & JSS2 & $289(24.1)$ \\
\hline & JSS3 & $198(16.5)$ \\
\hline & SSS1 & $148(12.3)$ \\
\hline & SSS2 & $312(26.0)$ \\
\hline & SSS3 & $121(10.1)$ \\
\hline \multicolumn{3}{|c|}{ Religion } \\
\hline & Christianity & $836(69.7)$ \\
\hline & Islam & $331(27.6)$ \\
\hline & Traditional & $27(2.3)$ \\
\hline & Others & $6(.5)$ \\
\hline \multicolumn{3}{|c|}{ Ethnicity } \\
\hline & Yoruba & $785(65.4)$ \\
\hline & Igbo & $341(28.4)$ \\
\hline & Hausa & $74(6.2)$ \\
\hline \multicolumn{3}{|c|}{ Parents' education level } \\
\hline & No formal education & $173(14.4)$ \\
\hline & Primary school & $214(17.8)$ \\
\hline & Secondary school & $268(22.3)$ \\
\hline & OND/NCE & $182(15.2)$ \\
\hline & BSc/HND & $318(26.5)$ \\
\hline & Postgraduate & $45(3.8)$ \\
\hline \multicolumn{3}{|c|}{ Parental SES } \\
\hline & Lower & $629(52.4)$ \\
\hline & Middle & 443 (36.9) \\
\hline & Higher & $128(10.7)$ \\
\hline
\end{tabular}




\subsection{Test of Hypotheses}

Hypothesis 1: There is no significant joint contribution of socio-demographic variables on LTPA among adolescents in Southwest States, Nigeria.

Table 2: Regression table showing the joint contribution of socio-demographic variables on LTPA among adolescents in Southwest States, Nigeria

\begin{tabular}{|c|c|c|c|c|c|}
\hline \multicolumn{6}{|c|}{$\begin{array}{l}\mathrm{R}=.280 \\
\text { Multiple } \mathrm{R}=.432 \\
\text { Multiple } \mathrm{R}^{2} \text { adjustment }=.326 \\
\text { Standard Error Estimate }=10.75913 \\
\text { Analysis of Variance }\end{array}$} \\
\hline Model & $\begin{array}{c}\text { Sum of } \\
\text { square }\end{array}$ & Df & Mean square & $\mathbf{F}$ & $\mathbf{P}$ \\
\hline Regression & 4612.274 & 8 & 576.534 & \multirow[t]{3}{*}{4.980} & \multirow[t]{3}{*}{.000} \\
\hline Residual & 137868.825 & 1191 & 115.759 & & \\
\hline Total & 142481.099 & 1199 & & & \\
\hline
\end{tabular}

Table 2 reveals that the joint contribution of Socio-demographic variables on LTPA among adolescents in Southwest States, Nigeria is significant $(F(8,1191)=4.980, p<.05)$. The independent variable also yielded a coefficient of multiple regression (R) of .280 meaning that about $28 \%$ of the variation is accounted for by the independent variables. Therefore, the null hypothesis is rejected.

Hypothesis 2: There is no significant relative contribution of socio-demographic variables on LTPA among adolescents in Southwest States, Nigeria

Table 3: Regression table showing relative contribution of socio-demographic variables (age, gender, religion, ethnicity, parent's level of education, socioeconomic status, frequency of participation, number of children and family supports) on LTPA among adolescents in Southwest States, Nigeria

\begin{tabular}{|c|c|c|c|c|c|c|}
\hline \multirow{2}{*}{\multicolumn{2}{|c|}{ Model }} & \multicolumn{2}{|c|}{$\begin{array}{l}\text { Unstandardized } \\
\text { Coefficients }\end{array}$} & \multirow{3}{*}{$\begin{array}{c}\begin{array}{c}\text { Standardized } \\
\text { Coefficients }\end{array} \\
\text { Beta } \\
\end{array}$} & \multirow[t]{2}{*}{$\mathrm{T}$} & \multirow[t]{2}{*}{ Sig. } \\
\hline & & B & Std. Error & & & \\
\hline \multirow[t]{10}{*}{1} & (Constant) & 67.776 & 2.375 & & 28.539 & .000 \\
\hline & Age & .273 & .360 & .022 & .760 & .448 \\
\hline & Gender & .401 & .672 & .018 & .597 & .551 \\
\hline & Religion & 1.651 & .617 & .083 & 2.675 & .005 \\
\hline & Ethnicity & .360 & .517 & .023 & .697 & .486 \\
\hline & Parents' level of education & .980 & .283 & .103 & 3.466 & .001 \\
\hline & Parents SES & 1.464 & .504 & .109 & 2.906 & .004 \\
\hline & $\begin{array}{l}\text { Frequency of participation } \\
\text { in LTPA }\end{array}$ & .309 & .533 & .020 & .579 & .562 \\
\hline & No of children in your family & 1.496 & .396 & .128 & 3.776 & .000 \\
\hline & Family support & .130 & .289 & .013 & 1.449 & .654 \\
\hline
\end{tabular}


Table 3 shows for each socio-demographic variable, the unstandardised regression weight ( $ß)$, the standardized error of estimate (SEß), the standardized coefficient, the tratio and the level at which the t-ratio is significant. The table revealed that number of children in the family has the highest contribution of $13 \%(B=128, t=3.776, p<0.05)$ followed by parental socio-economic status with the contribution of $11 \%(\beta=.109, \mathrm{t}=$ $2.906, \mathrm{p}<0.04$ ) followed by parents' level of education with the contribution of $10.3 \%$ (B $=.103, \mathrm{t}=3.446, \mathrm{p}<0.01)$ followed by religion with the contribution of $8.3 \%(\Omega=.083, \mathrm{t}=$ $2.675, \mathrm{p}<0.05)$ followed by ethnicity with the contribution of $2.3 \%(\beta=.023, t=0.677, \mathrm{p}>$ $0.05)$ followed by age with the contribution of $2.2 \%(\beta=.022, t=0.760, p>0.05)$ followed by the frequency of participation in leisure time physical activity with the contribution of $2 \%(\beta=.020, t=0.579, p>0.05)$ while gender has the least contribution of $2 \%(\beta=.018, t=$ $0.597, \mathrm{p}>0.05)$. Therefore, the null hypothesis is rejected.

Hypothesis 3: There is no significant joint contribution of psychological variables on LTPA among adolescents in Southwest States, Nigeria.

Table 4: Regression table showing joint contribution of psychological variables (self-efficacy and motivation) on LTPA among adolescents in Southwest States, Nigeria

\begin{tabular}{|c|c|c|c|c|c|}
\hline \multicolumn{6}{|l|}{$\mathrm{R}=.990$} \\
\hline \multicolumn{6}{|c|}{ Multiple $\mathrm{R}=.981$} \\
\hline \multicolumn{6}{|c|}{ Multiple $\mathrm{R}^{2}$ adjustment $=.981$} \\
\hline \multicolumn{6}{|c|}{ Standard Error Estimate $=1.50118$} \\
\hline \multicolumn{6}{|c|}{ Analysis of Variance } \\
\hline Model & Sum of square & Df & Mean square & $\mathbf{F}$ & $\mathbf{P}$ \\
\hline Regression & 139783.621 & 2 & 69891.811 & \multirow[t]{3}{*}{31014.342} & \multirow[t]{3}{*}{.000} \\
\hline Residual & 2697.478 & 1197 & 2.254 & & \\
\hline Total & 142481.099 & 1199 & & & \\
\hline
\end{tabular}

Table 4 reveals that the joint contribution of psychological variables (self-efficacy and motivation) on leisure time physical activity among Southwest States is significant (F $(2,1197)=31014.342, \mathrm{p}<.05)$. The independent variable also yielded a coefficient of multiple regression ( $R$ ) of .990 meaning that about $99 \%$ of the variation is accounted for by the independent variables. Therefore, the hypothesis is rejected.

Hypothesis 4: There is no significant relative contribution of psychological variables on LTPA among adolescents in Southwest States, Nigeria.

Table 5: Regression table showing the relative contribution of psychological variables (self-efficacy and motivation) on LTPA among adolescents in Southwest States, Nigeria

\begin{tabular}{|c|c|c|c|c|c|c|}
\hline \multirow{2}{*}{\multicolumn{2}{|c|}{ Model }} & \multicolumn{2}{|c|}{$\begin{array}{c}\text { Unstandardized } \\
\text { Coefficients }\end{array}$} & \multirow{3}{*}{$\begin{array}{c}\begin{array}{c}\text { Standardized } \\
\text { Coefficients }\end{array} \\
\text { Beta } \\
\end{array}$} & \multirow[t]{2}{*}{$\mathbf{T}$} & \multirow[t]{2}{*}{ Sig. } \\
\hline & & B & Std. Error & & & \\
\hline \multirow[t]{3}{*}{1} & (Constant) & 2.214 & .296 & & 7.485 & .000 \\
\hline & Motivation & .116 & .000 & .990 & 249.054 & .000 \\
\hline & Self-efficacy & .002 & .006 & .651 & 21.289 & .013 \\
\hline
\end{tabular}


Table 5 shows for each psychological variable, the unstandardised regression weight (ß), the standardized error of estimate (SEß), the standardized coefficient, the t-ratio and the level at which the $t$-ratio is significant. The table reveals that motivation has the highest contribution of $99.0 \%(B=.990, t=249.054, p<0.05)$, while self-efficacy has the least contribution of $65.1 \%(B=.651, t=21.289, \mathrm{p}<0.05)$. Thus, the hypothesis is rejected.

\section{Discussion}

This study examined socio-demographic and psychological determinants of LTPA among adolescents in Southwest, Nigeria. Both socio-demographic and psychological factors significantly determined LTPA in the study. Nine socio-demographic factors of (age, gender, religion, ethnicity, parent's level of education, parent's SES, frequency of participation, number of children in the family and Family support) were examined and only four factors of (religion, parent's level of education, parent's SES and number of children) are significant to LTPA participation, while five factors of (age, gender, ethnicity, frequency of participation and family support) were not significant.

The findings in relation to the age of the participants in this study is in agreement with the study conducted by Marques et al. (2015) which examined the link between socio-demographic factors and engagement in the recommended PA level for Portuguese adults revealed that age was not significantly related with PA. Payne, Townsend and Foster (2013) proved that along with the increasing pupils' age, their participation in active forms of recreation declines, particularly among girls. The findings of this study indicated that gender had the least contribution to LTPA of the participants. This corroborates with the study of Jandric (2010) who revealed that the difference in social role of boys and girls lead to a different participation and understanding towards PA participation, the author further showed that boys were more likely to be physically active than girls, because girls recorded significantly fewer activities involving games than the boys did. While Lubowiecki-Vikuk and Biernat (2017) showed that as for girls, the risk of lack of movement was more than 1.4 times higher than among boys.

This study showed that religion significantly determined LTPA among adolescents. This could be attributed to greater number of participants who were Christians who perform different roles in church and perform such activities as singing, dancing, clapping and some acrobatic displays in few churches, while the Muslim counterparts are found of demonstrating flexibility-related activities as bending and squatting when praying. The finding is in accordance with the study of Nagel \& SgoutasEmch (2007) and Benjamins (2012) that identified stronger influence of religious beliefs on health behaviour that is associated with physical activity, but not diet and alcohol consumption. Ethnicity was not a significant determinant of LTPA among adolescents. This is supported by Adegoke and Oyeyemi (2011) who showed that ethnicity was partly associated with high prevalence of physical inactivity. The authors added that participants who belong to the Hausa ethnic group reported the highest prevalence of physical inactivity, while estimates from the 2007 National Health Interview Survey 
(NHIS) indicated significant differences in PA across racial groups in which $33.8 \%$ of Whites, $23.8 \%$ of Hispanics and $23.2 \%$ of Blacks engage in regular leisure PA (Saffer, Dave \& Grossman, 2011).

Parents' level of education significantly determined LTPA among adolescents. This finding could be attributed to the participant's parent's awareness and campaigns on benefits associated with LTPA they listened to, watched on television and read about from various sources such as media and their places of work. This is supported by the study of Shibata et al. (2009); Marques et al. (2015)] in Japan and Portugal respectively, they showed that the most educated were more likely to attain the recommended PA levels. Furthermore, the study found that parent's SES was a significant determinant of LTPA. This coincides with the findings of Marques et al., (2015); Dias-da-Costa, et al., (2005) that higher and middle SES adults are more likely to follow preventive programmes and health-promoting behaviour, whether due to greater motivation or access to resources.

Moreover, frequency of participation was not a significant determinant of LTPA among adolescents. This could be attributed to the fact that most of the participants did not participate in LTPA outside the four walls of the school. This corroborates with the study of Ndagire, Muyonga and Nakimbugwe (2019) in Uganda and Liu \& Dai (2017) in China, who showed the inadequate and low levels of PA, while the female students engaged in less physical activity than male students. The findings of this study is not surprising, because most of the adolescents are yet to attain the recommendations made by WHO for children and youth aged 5-17years to accumulate at least 60min of MVPA daily. In addition, the number of children in the family is a significant factor that determines LTPA. This finding could be linked with the presence of more children in the family as some many families have an average of four children. Similarly, the studies of Davison (2004), Bagley, Salmon and Crawford (1998) reported that siblings influenced PA behaviour of children and found that girls with siblings spent more minutes per day in PA compared with girls without siblings. In contrast, Wang \& Qi (2016) revealed that there was no significant difference in MVPA time between adolescents living with one sibling and those without siblings.

Findings on family support was not significant. This could be said that some parents give priority to high academic involvement and achievement without considering the crucial role that LTPA could play in enhancing children's mental ability. This is similar to the study conducted by Aljayyousi et al. (2019) who found that some students mentioned that their families give priority to work, personal and family commitments, and academic achievement over physical activity. Yao and Rhodes (2015) concluded that the relationship between father-son PA modeling was higher than mother-son PA modeling, yet the findings were similar for the relationship between mother-daughter and father-daughter PA modeling. The parental style towards female was usually more restricted and tends to shape with sedentary activity.

The findings indicated that psychological indices of motivation and self-efficacy determined LTPA among adolescents. The study further revealed that motivation has the 
highest contribution of $99 \%$, while self-efficacy has $65.1 \%$. This could be attributed to the interest, enjoyment, fun, happiness, skill mastery and having good time with friends. Similarly, Ajibua, Olorunsola and Bewaji (2013); Andrea in Jonathan (2016) who indicated that the motivation for physical activity was found to be the largest contributor or effect on the frequency and magnitude of participation in LTPA among students. Reasons for participation in LTPA were personal motivation/interest, integrated regulation, and identified regulation, while Biddle and Mutrie (2008) reported that for children and youth, common motives were fun, skill development, affiliation, fitness, success and challenge; whereas for adults, motives change across stages of the lifecycle. The findings on self-efficacy coincides with the study carried out by Chiu and Kayat (2010) indicated that high self-efficacy and motivation for physical activity would likely increase the rate of participation in LTPA among undergraduate students. (Hagger, Chatzisarantis \& Biddle, 2002; Liu, \& Dai, 2017) showed significant and moderate correlations between self-efficacy and physical activity participation among both young and older people.

\section{Conclusion}

The study demonstrated that the level of participation in LTPA was very low compared to WHO's recommendations of MVPA for the adolescents. The study further demonstrated that socio-demographic and psychological factors significantly determined LTPA among adolescents in Southwest, Nigeria. The findings suggest that socio-demographic and psychological factors could be the important factors to take into account in the designing and development of effective interventions to increase LTPA levels throughout the life course among adolescents in Southwest, Nigeria. More research on this topic is warranted.

\section{Acknowledgments}

The authors are grateful to the adolescents who participated in this study, schools' administrators, teachers, and the entire research team.

\section{Declaration of Conflicting Interests}

The authors declare no potential conflicts of interest with respect to the research, authorship, and/or publication of this article.

\section{About the Authors}

Solomon B. Oguntuase is a PhD student at the Department of Sports Psychology, School of Sports Science, Tianjin University of Sport, Tianjin, China.

Sun Yanlin is a Professor, Ed.D, Sport \& Exercise Psychology, Dean, School of Physical Education and Educational Science, Tianjin University of Sport, Tianjin, China. 
Tolulope C. Apata is a Fitness Trainer, Exercise Physiologist, Master's Degree holder in Exercise Physiology from Department of Human Kinetics, Faculty of Education, University of Ibadan, Ibadan, Nigeria.

Jephtah O. Ogunsanya $(\mathrm{PhD})$, is a Chief Lecturer at the Department of Physical and Health Education, Emmanuel Alayande College of Education, Oyo State, Nigeria. His area of specialization is Sports Psychology with research interest in psychological indices for performance enhancement, physical activity, sports participation and development.

\section{References}

Adegoke, B. \& Oyeyemi, A. L. (2011). Physical inactivity in Nigerian young adults: prevalence and socio-demographic correlates. Journal of Physical Activity and Health, 8, $1135-1142$

Ajibua M. A., Olorunsola H. K. \& Bewaji O. B. (2013). Perceived motivational factors influencing leisure-time physical activity involvement of teaching and nonteaching staff in tertiary institutions in Ondo State, Nigeria. International Journal of Asian Social Science 3 (1):10-19

Ajibua, M. A, Babalola, A. J. \& Oyesegun, O. O. (2014). Perceived motives for participation in leisure-time physical activity among employees of tertiary institutions in Ondo State, Nigeria. Journal of Education \& Human Development March, 3 (1), 559-571

Ajibua, M. A. \& Dominic, O. L. (2018). Quantification of leisure-time physical activity among university students in South-west, Nigeria. Journal of Physical Education and Sport $13(1), 72-78$.

Akarolo-Anthony, S. N., \& Adebamowo, C. A. (2014). Prevalence and correlates of leisure-time physical activity among Nigerians. BMC Public Health 14 (1): 529. doi:10.1186/1471-2458-14-529. http://dx.doi.org/10.1186/1471-2458-14-529

Aljayyousi, G. F., Munshar, M. A., Al-Salim, F. and Osman, E. (2019). Addressing context to understand physical activity among Muslim university students: the role of gender, family, and culture. BMC Public Health 19:1452, 1-12

Allison, K. R., Dwyer, J. J. M. and Makin, S. (1999). Self-efficacy and participation in vigorous physical activity by high school students. Health Education and Behavior, 26(1):12-24

Awotidebe, T. O., Adedoyin, R. A., Adegbesan, O. A., Babalola, J. F., Olukoju, I. O., Mbada, C. E. Chirwa, E. \& Bisiriyu, L. A. (2014). Psychosocial correlates of physical activity among university students. International Journal of Sports Science, 4(6): 205-211 DOI: 10.5923/j.sports.20140406.01

Bagley, S. Salmon, J. \& Crawford, D. (2006). Family structure and children's television viewing and physical activity, Medicine and Science in Sports and Exercise, 38, 5, 910-918 
Bandura, A. (1997). Self-efficacy: The exercise of control. New York: W. H. Freeman and Company

Benjamins, M. R. (2012). Religious beliefs, diet and physical activity among Jewish adolescents. Journal for the scientific study of religion, 51 (3), 588-597

Biddle S. J. H. \& Mutrie N. (2008). Psychology of physical activity. Determinants, wellbeing and interventions. $2^{\text {nd }}$ Edition, Routledge, London.

Cagla, E., Canlan, Y. \& Demir, M. (2009). Recreational exercise motives of adolescents and young adult. Journal of Human Kinetics, 12: 83-89.

Chida, Yoichi, Andrew Steptoe, and Lynda H. Powell (2009). Religiosity/spirituality and mortality. Psychotherapy and Psychosomatics 78: 81-90.

Chigbu, C. O., Berger, U. Aniebue, U. \& Parhofer, K. G. (2020). Physical activity and outdoor leisure time physical exercise: A population study of correlates and hindrances in a resource-constrained African setting. Journal of Multidisciplinary Healthcare, 13: 1791-1799. Doi http://doi.org/10.2147/JMDH.528158

Chinapaw, M. J., Slootmaker, S. M., Schuit, A. J., van Zuidam, M., van Mechelen, W. (2009). Reliability and validity of the Activity Questionnaire for Adults and Adolescents (AQuAA). BMC Med Res Methodol 9, 58.

Chiu, L. K. \& Kayat, K. (2010). Psychological determinants of leisure time physical activity participation among Public University Students in Malaysia. AJTLHE 2, (2), 33-45

Davison, K. (2004). Activity-related support from parents, peers, and siblings and adolescents' physical activity: are there gender differences? Journal of Physical Activity and Health, 1,4, 363-376.

de Moraes A. C, Guerra, P. H, Menezes, P. R. (2013). The worldwide prevalence of insufficient physical activity in adolescents; a systematic review. Nutr Hosp;28 (3): $575-584$.

Dias da Costa, J. S., Hallal, P. C., Wells, J. C., Daltoe, T., Fuchs, S. C., Menezes, A. M. \& Olinto, M. T. (2005). Epidemiology of leisure-time physical activity: a populationbased study in southern Brazil. Cadernos de Saude Publica.;21:275-282. doi: 10.1590/S0102-311X2005000100030

Dishman, R. K., Hales, D. P., Sallis, J. F., Saunders, R., Dunn, A. L., Bedimo-Rung, A. L., \& Ring, K. B. (2010). Validity of social-cognitive measures for physical activity in middle-school girls. Journal of Pediatric Psychology, 35(1), 72-88.

Duncan, S. C., Duncan T. E., Strycker, L. A. \& Chaumeton, N. R. (2004). A multilevel analysis of sibling physical activity. J Sport Exerc Psychol. 26:57-68

Fitzgerald, A., Fitzgerald, N., \& Aherne, C. (2012). Do peers matter? A review of peer and/or friends' influence on physical activity among American adolescents. Journal of Adolescence, 35(4), 941-958. doi: http://dx.doi.org/10.1016/j.

Guthold, R., Cowan, M. J., Autenrieth, C. S., Kann, L. \& Riley, L. M. (2010). Physical activity and sedentary behavior among school-children: a 34-country comparison. J Pediatr.157(1):43. 
Hagger, M. S., Chatzisarantis, N. \& Biddle, S. J. H. (2002). A meta-analytic review of the theories of reasoned actions and planned behaviour in physical activity: Predictive and the contribution of additional variables, Journal of Exercise Psychology 24: 332.

Hallal, P. C., Andersen, L. B., Bull, F. C., Guthold, R., Haskell, W., Ekelund U., et al. (2012). Global physical activity levels: surveillance progress, pitfalls, and prospects. Lancet; 380(9838):247-257. doi: 10.1016/S0140-6736(12)60646-1.

Jandric, S. (2010). Differences between boys and girls in terms of physical activity. Physical Education and Sport, 8(1), 1-7

Jonathan, M., Y. (2016). Leisure time physical activity participation motivation of secondary school student in Hong Kong. Thesis submitted to the Department of Physical Education, Hong Kong Baptist University for the award of Bachelor of Social Sciences (Honours) in Sport and Recreation Leadership.

Kahn, J. A., Huang, B., Gillman, M. W., Field, A. E., Austin, S. B., Colditz, G. A. \& Frazier, A. L. (2008). Patterns and Determinants of Physical Activity in U.S. Adolescents. J Adolesc Health. 42:369-377. doi: 10.1016/j.jadohealth.2007.11.143.

Kjonniksen, L., Torsheim, T., \& Wold, B. (2008). Tracking of leisure-time physical activity during adolescence and young adulthood: a 10-year longitudinal study. Int J Behav Nutr Phys Act5, 69

Lee, I. M., et al. (2012). Effect of physical inactivity on major non-communicable diseases worldwide: an analysis of burden of disease and life expectancy, The Lancet, 380: 219-29

Liu, H. \& Dai, X. (2017). Correlation between physical activity and self-efficacy in Chinese university students. Journal of Sport Psychology, 26, (4), 110-114

Lo, F. E., Tsai, F. C., Lee, M. B., Tsai, L. T., Lyu, S. Y., \& Yang, C. C. (2015). Contextual factors influencing leisure physical activity of urbanized indigenous adolescents. Journal of the Formosan Medical Association, 114 (11), 1082-1087. DOI: 10.1016/j

Loucaides, C. A. (2009). School location and gender differences in personal, social, and environmental correlates of physical activity in Cypriot middle school children. Journal of Physical Activity \& Health, 6(6), 722-730.

Lubowiecki-Vikuk, A., \& Biernat, E. (2017). Socio-demographic determinants of leisure time physical inactivity of adolescents from the Voivodeships of Central Poland. Central European Journal of Sport Sciences and Medicine I Vol. 17, No. 1/2017: $41-50$

Marques A. et al. (2015). Socio-demographic correlates of leisure time physical activity among Portuguese adults. Cad. Saúde Pública, Rio de Janeiro, 31(5):1061-1070

McMinn, A. M., van Sluijs, E. M. F., Wedderkopp, N., Froberg, K., \& Griffin, S. J. (2008). Sociocultural correlates of physical activity in children and adolescents: findings from the Danish arm of the European Youth Heart Study. Pediatric Exercise Science, 20(3),319-33 
Mukona, D., Munjanja, S. P., Zvinavashe, M., \& Stray-Pederson, B. (2016). Physical activity in pregnant women in Africa: A systematic review. International Journal of Nursing and Midwifery, 8, 28-34

Muller, A. M., Khoo, S. \& Lambert, R. (2013). Review of physical activity prevalence of Asian school-age children and adolescents. Asia Pac J Public Health;25(3):227-238.

Nagel, E. \& Sgoutas-Emch, S. (2007). The relationship between spirituality, health beliefs, and health behaviors in college students. Journal of Religion and Health 46: 14154.

Ndagire, C. T., Muyonga, J. H. \& Nakimbugwe, D. (2019). Fruit and vegetable consumption, leisure- time physical activity, and sedentary behavior among children and adolescent students in Uganda. Food Sci Nutr.;7:599-607. https://doi.org/10.1002/fsn3.883

Oyeyemi, A. L., Ishaku, C. M., Oyekola, J., Wakawa, H. D., Lawan, A., Yakubu, S., \& Oyeyemi, A. Y. (2016). Patterns and associated factors of physical activity among adolescents in Nigeria. Plos One, 11(2), 1-16

Payne, S., Townsend, N., \& Foster, C. (2013). The physical activity profile of active children in England. International Journal of Behavioral Nutrition and Physical Activity, 10, 136. doi: 10.1186/1479-5868-10-136

Petosa, R. J., Hortz, B. V., Cardina, C. E. \& Suminski, R. R. (2005). Social cognitive theory variables associated with physical activity among high school students. International Journal of Sports Medicine, 26, 158-163.

Rimmer J. H., Nicola T., Riley B. \& Creviston T. (2002). Exercise training for African Americans with disabilities residing in difficult social environments. Am J Prev Med., 23(4):290-295

Saffer, H., Dave, D. M. \& Grossman, M. (2011). Racial, ethnic and gender differences in physical activity. Working Paper 17413. http://www.nber.org/papers/w17413

Sallis J., Prochaska J. \& Taylor, W. (2000). A review of correlates of physical activity of children and adolescents. Med Sci Sports Exerc.; 32:963-975. [PubMed]

Sedibe, H. M., Kahn, K., Edin, K., Gitau, T. \& Ivarsson, A. (2014). Norris AS. Qualitative study exploring healthy eating practices and physical activity among adolescent girls in rural South Africa. BMC Pediatrics; 14:211. PMID:25164604

Shibata, A., Oka, K., Nakamura, Y. \& Muraoka I. (2009). Prevalence and demographic correlates of meeting physical activity recommendation among Japanese adults. J Phys Act Health, 6:24-32

Shokrvash, B., Majlessi, F., Montazeri, A., Nedjat, S., Rahimi, A., Djazayeri, A., \& Shojaeezadeh, D. (2013). Correlates of physical activity in adolescence: a study from a developing country. Global Health Action, 6, 20327-20327. doi: 10.3402/ghav6i0.20327

Zach, S., Bar-Eli, M. Morris, T. \& Moore, M. (2012). Measuring motivation for physical activity: An Exploratory Study of PALMS - The physical activity and leisure motivation scale. Nova Science Publishers 
Telama, R. (2009). Tracking of physical activity from childhood to adulthood: A review. Obes Facts2, 187-195

Wojtyła, A., Biliński, P., Bojar, I., \& Wojtyła, K. (2011) Physical activity among junior high school adolescents in Poland. Problemy Higieny i Epidemiologii, 92, 335-3

World Health Organization (2014). Global recommendations on physical activity for health. Retrieved: December 15, 2017 from http://whqlibdoc.who.int/publications/2010/9789241599979 eng.pdf

World Health Organization (WHO). (2015). Physical activity strategy for the WHO European Region 2016-2025. Retrieved: December 18, 2017 from http://www.euro.who.int/ data/assets/pdf file/0010/282961/65wd09e PhysicalA ctivityStrategy 150474.pdf

World Health Organization (2017b). Physical activity and young people. Recommended levels of physical activity for children aged 5-17 years. Available from: http://www.who.int/dietphysicalactivity/factsheet young people/en/ Accessed on June 07,2021

World Health Organization (2005). Regional committee for Africa. Diseases in the African region: current situation and perspective. Maputo: World Health Organization.

World Health Organization Prevalence of insufficient physical activity. (2018). https://www.who.int/news-room/fact-sheets/detail/physical-activity. Accessed on June 07, 2021.

Yao, C. A. \& Rhodes, R. E. (2015). Parental correlates in child and adolescent physical activity: a meta-analysis. The International Journal of Behavioral Nutrition and Physical Activity BioMe. 

copy, distribute, transmit or adapt the article content, providing a proper, prominent and unambiguous attribution to the authors in a manner that makes clear that the materials are being reused under permission of a Creative Commons License. Views, opinions and conclusions expressed in this research article are views, opinions and conclusions of the author(s). Open Access Publishing Group and European Journal of Physical Education and Sport Science shall not be responsible or answerable for any loss, damage or liability caused in relation to/arising out of conflict of interests, copyright violations and inappropriate or inaccurate use of any kind content related or integrated on the research work. All the published works are meeting the Open Access Publishing requirements and can be freely accessed, shared, modified, distributed and used in educational, commercial and non-commercial purposes under a Creative Commons attribution 4.0 International License (CC BY 4.0). 